\title{
The Role of Short Food Supply Chains in Greece -- What Opportunities for Sustainable, Just and Democratic Food Systems at Times of Crisis?
}

\author{
Eugenia A Petropoulou
}

Department of Sociology, University of Crete, Greece

Copyright $\subset 2016$ by authors, all rights reserved. Authors agree that this article remains permanently open access under the terms of the Creative Commons Attribution License 4.0 International License

\begin{abstract}
Criticism against agro-industrial food systems and intense farming practices is increasing. Local food chains have emerged as a promising approach for transitions towards sustainable food systems (in terms of environment, socio-economic equity and regional development) $[1,2]$. The currently dire economic situation in Greece has 'stimulated' the emergence of alternative local food chains enabling the economic crisis to be understood within the context of resilience [3]. This paper aims to examine resilience as the ability of people, groups or communities to cope with external stresses and disturbances resulting from social, political and environmental change. A relatively new tendency could also be viewed as part of a wider revival of socially-motivated and solidarity based economic activities in the past decade. Local short food chains exist in a range of forms in both commercial and non-commercial settings. A comparison of different types of 'short' food networks is useful and will be presented. The methods employed will be based on a literature review, desktop research and information derived from an EU funded research project. Furthermore, key issues of the analysis will focus on activities, actors, type of products, area and territory, health and sustainability aspects, growth potential and innovation [cf. 4].
\end{abstract}

Keywords Local Food Chains, Sustainability, Resilience, Economic Crisis, Greece

\section{Introduction}

Short Food Supply Chains (SFSCs) have been established in parallel to conventional food chains, in response to the dominant industrial food system that distances and detaches food production from food consumption; and simultaneously are increasingly taken into consideration by policy and decision makers [5]. This alternative approach to the dominant agri-food regime as exemplified by SFSCs is best discernible in relation to the critical trends affecting Greek agriculture in the frame of industrialization and globalization process: increases to the value of land significantly contributes to the farmers' income, land abandonment and concentration of property, trade liberalization and the rising global competition and speculation on food as commodity, the dependency of local, small producers from public and EU subsides, multinational customers and large food retailers.

SFSCs can represent traditional and/or alternative ways of producing, distributing, retailing, and buying food. This means to refuse the main characteristics of traditional supply chains, such as extreme productivity, standardization and industrial organisation, while paying greater attention to other aspects, such as social and environmental quality, origin and organic production of agro-food products. In theory, farmers being part of this alternative food supply chain can (i) better program the speed and quantity of their harvests, (ii) enjoy the flexibility to sell what they produce in line with seasonality cutting down costs for conservation and storage, while they receive immediate payment at the delivery point avoiding the waiting times imposed by big retailers and (iii) can get direct feedback from consumers for future product and delivery improvement [6].

Originally, short food supply chains were associated primarily with a demand for social proximity: consumers wanted direct contact and relationships engendering trust with producers. Recently SFSCs have been considered as niches of new social relationships for those food system actors, mostly producers and consumers, who look for alternatives to the globalized agri-food model [4]. The growing interest in short food supply chains also reflects consumer demand for quality and traceability, given the alarming health crises in food markets [7], [8]. Also policies that favour more traceable supply chains have been widely implemented [8]. These policies encourage retailers to source directly from farmers rather than from channels that involve several layers of anonymous transactions. The main concerns driving this policy shift include issues related to health, safety, quality, and productivity. Most importantly, 
reducing supply chain barriers is expected to reduce prices and, thus, to offer consumers cheaper and healthier access to fresh fruits and vegetables. [9].

Along these lines the framework used for sourcing SFSCs as conceptualised and presented in the existing literature contains four parameters that go beyond the conventional and classical definitions of short food chain [10]:

- An attempt to connect consumers, producers and food, in a new economic space which re-embeds food production and consumption.

- Non-conventional supply/distribution channels detached from industrial supply and demand distribution and corporately controlled food chains.

- Adopted principles of social -embeddedness founded or working on the principles of trust, community and often linked with a specific geographical location.

- Based around a notion of 'quality' - promotes quality, either conventional or alternative, preserving traditions or heritage [10, p. 253].

Several typologies have been formulated to classify short food supply chains identified by empirical research. In terms of the organisational structure and the specific mechanism entailed in the extended relations of SFSCs in time and space, three main types of them can be identified based on the number of intermediaries, physical distance and organisational arrangements $[5,10,11$ p.25-27]:

- Face-to-face: consumer purchases a product direct from the producer/processor on a face-to-face basis. Authenticity and trust are mediated through personal interaction. The internet presents opportunities for a variant of face-to-face trading -although more recent research by Canavan [12] has to some extent problematised the extent to which internet trading can replicate the experience of buying direct from the person who has made the food. Examples of face-to-face SFSCs are: farm gate sales, Pick-Your-Own, farm shops, farmers markets, roadside sale.

- Spatial proximity: products are produced and retailed in the specific region of production, and consumers are made aware of the 'local' nature of the product at the point of sale. This category overlaps with the 'face-to-face' category and includes the same retail spaces as noted above. In addition, this category could include specialist retailers (e.g. delicatessens, bakeries, butchers, grocers) which sell 'local' produce and also elements of the hospitality industry which sell local foods (e.g. restaurants, pubs, hotels and other accommodation). This category could also include public sector food provision, such as hospitals, schools, universities, care homes, prisons and so on which either sell or provide locally sourced foods.

- Spatially extended: information about the place and processes of production is communicated to consumers who are outside of the region of production itself, and may have no personal experience of that region. All types of retail space are potentially appropriate for this type of SFSC. The product information is communicated through product packaging and promotion, branding, and the use of certification and legislation to protect named products with distinct geographical origin. The main examples are PDO (Protection of Designated 27 Origin) or PGI (Protected Geographical Indications) [11]. This legally enforced system sidesteps the whole problem of defining 'the local' itself. Therefore, what the consumer can rely on is not whether the product has been produced within a defined radius from the point of sale (as in a local food system), but that it has been produced in a distinct area defined by the presence of a unique combination of soils, topography, climate, and locally embedded skills and knowledge. Products registered under such schemes therefore do not have to be retailed locally they can be exported -and this offers opportunities for producers to benefit from bigger markets. As noted by Renting [7], the transaction costs resulting from the need for certification, and of course distribution, mean that spatially extended SFSCs are often occupied by larger businesses [11 p. 26-27].

Moreover, according to Mount [13], SFSCs beyond organising and providing food in many social and geographical areas, they potentially contribute to the axis sustainable food systems, rural development and health communities. However, a second dimension of SFSCs is considered in the literature that of 'quality'. Two distinguished positions of the quality definition and its conventions were identified by Renting [7 pp. 401-402].

- The first focuses on the link between quality attributes and the place of production or producer. This relationship is complex in nature and entails cultural as well as historical elements that are integrated into the product satisfying thus consumer needs for a highly qualified end food product.

- The second position of SFSCs defines quality in terms of bioprocesses by taking into consideration the natural intrinsic characteristics of the product, entailing consequently a reliable access to health and safety for individuals and communities [7, pp.401-402].

More precisely, perception of quality reflects an increase in the so-called ethical food consumption, the aim of which is to spur social, economic, or environmental change though individual decisions on what, how and when to buy. In addition, food quality is an extension of personal needs such as food safety and the way in which food is produced in terms of impact on the environment, ethical content (fair wages, animal welfare), and the area where production takes place $[14,15]$. As for the latter, a growing subset of consumers is in search of alternative sources of food produced close to their place of residence [16, 17]. Although short food supply chains are normally associated with better 
product quality or more sustainable production and commercial practices, these characteristics do not develop automatically since production location alone does not guarantee the attributes of quality and safety, nor that the products have a low environmental impact or include social responsibility attributes [8].

The objective of this paper is to focus on the characteristics and the diversity of typical SFSCs, which go beyond geographical nearness and no or limited number of intermediaries between producers and consumers. Particular emphasis is placed on the contribution of SFSCs to sustainability and health, as well as to the social relationship between consumers and producers. Examples of how SFSCs have increased sustainability are illustrated below [11 p.10]:

Health \& wellbeing: Some SFSCs have increased knowledge and concern about food amongst consumers and led to the adoption of healthier diets.

Environmental: Many SFSCs have minimized the use of resources such as fossil fuel or packaging, and/or use of less polluting methods of production (e.g. organic farming).

Social: The direct relationship between producer(s) and consumer(s) has ensured fairness and trust in many SFSCs, more social inclusion of people. SFSCs also can contribute to revitalize local communities in multiple ways (e.g. working places, strengthening local networks).

Economic: SFSCs to which consumers are committed in a more long-term perspective have reduced economic uncertainties. They help to preserve small and medium farms. SFSCs increase or help re-circulate community income and create new jobs; however the degree and relevance might strongly differ between SFSCs.

Within this framework, the degree of sustainability varies among different types of SFSCs, their products, locations and the provision of specific common goods such as: health and environmental protection to participants - consumers. Various participants in SFSCs may interpret sustainability differently and experience different impacts. Short food supply chains (SFSCs) can therefore act as a driver of change and a method to increase sustainability, trust, equality and growth in agricultural, food, social, health and rural policy areas.

SFSCs are therefore varied in nature and practice. They exist in a range of forms in both commercial and non-commercial settings and attest a new kind of food politics including the creation of bottom-up participatory initiatives promoting an alternative economy particularly in countries confronting crises. Recent collective works have focused on sustainable community consumption practices [18] and more encompassing social innovation oriented practices and initiatives across the globe [19]. Based on the work by Nicholls and Murdock [20], 'social innovation' has been used to describe: 1) societal transformation; 2) a model of organizational management; 3) social entrepreneurship; 4) the development of new products, services and programmes; and, 5) a model of governance, empowerment and capacity building. Moulaert et al. [19] discusses social innovation as improving social relations at the micro level (between individuals) and the macro level (between classes and social groups). Therefore, civil society and individual citizens are often attempting to react and to seek new ways through 'social innovation' and, thus, new structures, hybrid organisations or a multitude of attempts across sectors are on the rise. Despite this strong involvement of civil society, and the fact that citizen engagement should be seen as a constant of social innovation policies and activities, social innovation can emerge from any sector. In general, the link between social innovation and the sustainable development agenda and policies is very apparent, especially with regards to social and equity issues. Concurrent to the above, SFSCs need to be analyzed by paying attention at the interplay between market, politics and culture [21]. The combination of these three realms produces a variety of meanings attached to consumerist practices: in the cultural sphere, since SFSCs promote alternative life styles and values, such as "responsible consumerism", "sustainable and solidarity-based economy", "social and economic justice", etc.; in the political sphere they help their members/activists to increase their social capital, to improve some aspects of their economic condition and to develop new civic awareness and democratic competencies; finally, in the market sphere, they try to go beyond the capitalist market setting by encouraging ongoing and direct relationships, mutual solidarity, and coproduction between producers and consumers [18]. Consequently, social innovation may refer to new products and services that address social needs, that is, products and services which help to build more sustainable, cohesive and inclusive societies. Within this framework, a comparison of four types of different SFSCs is presented in this paper: a) two "Face to Face initiatives; b) one proximate more complex SFSC and c) one spatially extended SFSC.

\section{Materials and Methods}

A new way of addressing social issues is often overlooked either by the private sector or the public sector. The emergence of fresh social solutions and methods although limited in number can adequately respond to the multiple social, economic, environmental and demographic crises that are faced by societies all over the world [22]. For example, in Europe, austerity, budget cuts, unemployment, ageing, migration, climate change and food security are only a few of the issues that can be cited as examples of the effects of such crises. Social innovation can be a means for addressing these challenges and to modernize the public institutions that are responsible for them. An increasing number of social innovations are using ICT (Information and Communication Technology), which includes online networks, communities and platforms, in the course of their activities and to achieve their goals. The methodological tools adopted in this research are partially derived from an EU funded project (LIVEWHAT http://www.livewhat.unige.ch, see section on 
acknowledgments) that makes use of the above mentioned technology. One of the actions of the project includes the identification of a wide range of networks, organizations and groups engaged in "alternative forms of resilience" as seen in recent solidarity and other social innovation practices across the nine countries which are involved in the project (e.g. alternative organizations and groups of social economy, co-operative structures, social enterprises, barter networks, food banks, time banks, alternative coins, free medical services, soup kitchens, etc.). Towards this direction the project organized and sampled the available online material in order to code and analyze it. For further details on the tools of network analysis please visit the link in brackets (http://www.livewhat.unige.ch/wp-content/uploads/2014/07 /Analysis-of-Web-Accessible-Networks-Organizations-andGroups.pdf).

Mapping organizations and activities online is becoming increasingly important and widespread among researchers interested in alternative forms of resilience offering them a precious source for investigating new social and political practices $[23,24]$. The rise of social media, blogs, and other online services has also changed the ways in which people interact and get involved in politics. They are the means to get their message through thus they make extensive use of this opportunity to communicate. For the purpose of this paper, the unit of analysis used is the so-called Alternative Action Organizations (AAOs) unit. AAO is "a collective body/unit that organizes collective or non-collective actions-events carrying out alternatives to dominant socio-economic and cultural practices with visible beneficiaries and claims" [25] on their economic and social well being - including basic needs, health, food, etc. Their actions (AAOs) are engaged in the public sphere and are not operated/fully supported by mainstream economic and political organizations (i.e. corporate, state, or EU related agencies). In addition their actions are characterized by a solidarity-based exchanging and cooperative framework aiming to provide people alternative ways of enduring day-to-day difficulties and challenges under hard economic times, which relate to urgent needs, such as the environment, communications, the economy, alternative forms of consumption and food security, self-organized spaces, culture, and others. The acting-organization can be formal or informal (citizen's initiatives, NGO's, social movement organizations, local government organizations, the church, etc.).

Alternative Action Organizations (AAOs) were drawn from related national 'hub/subhub' nodal-websites which have been identified and ranked at the national level by the project's nine teams on the basis of systematic google searches and the related literature. The hubs/subhubs selected for each country provide large number of links on AAOs and the best possible coverage of the main categories of alternative action types related to urgent needs, economy, energy and environment, civil media and communications, alternative consumption lifestyles etc. These nodal-websites comprise the resources from which the 'population' of AAOs is composed in order to draw a random sample of AAOs for coding purposes [26]. AAOs websites have been extracted from the databases of the highest ranked hubs/subhubs through a systematic process, while the resulting national populations have been checked for their adequacy, in terms of the above mentioned criteria, with a preview of their geographic dispersion and the percentages each action type contains.

Concurrent to the above information, the Greek SFSCs presented are units/bodies of strategic actions in the public sphere that are not connected directly or indirectly to the i.e. corporate, state, or EU related agencies. They are alternative economy organizations that engage in actions aiming at providing people and communities' alternative ways of enduring day-to-day difficulties and challenges under hard economic times that relate to consumption/food sovereignty, the environment, the economy, health and others.

A small number of Greek SFSCs(four in total number) were selected to the extent that they were active within the time frame of the recent global economic crisis (i.e. at least between 2007 and 2015) and offer information regarding issues of sustainability such as the economic, environmental, health and food consumption framework of SFSCs in Greece. The sample selection and criteria of inclusion for the aforementioned SFSCs are described as follows:

Following the procedure described above, the location of the Greek SFSCs was drawn from the Greek national hub enallaktikos.gr according to the criteria of: inclusiveness and diversity in terms of geographic origin and sustainability action type's coverage, along with the number of websites they contain. SFSCs websites have been extracted and checked by IT specialists through a systematic process and checked for their adequacy in terms of the sustainability and time framework criteria already mentioned (see also http://www.livewhat.unige.ch/wp-content/uploads/2014/07/ Analysis-of-Web-Accessible-Networks-Organizations-andGroups.pdf).

Finally, although the national/Greek investigation has been thorough, the small sample, the wide heterogeneity of SFSCs and the complexity of the methodological procedure suggests that the bellow analysis of SFSCs is still considered explorative and the results provisional.

\section{Analysis of Short Food Supply Chains in Greece}

In Greece many SFSCs are comparatively small scale and remain of local character. Only recently, since 2008, the sector experiences dynamic growth characterized by a diversity of SFSCs forms, sprouting of new initiatives as an outcome of interaction of various internal and external factors mostly stimulated by the country's current economic crisis. 


\subsection{Face to Face SFSCs}

Examples of Greek SFSCs include three main categories. In the first category a consumer purchases a product directly from the producer/processor on a face-to-face basis while authenticity and trust are mediated through personal interaction. Two cases are presented as illustrated in Table. 1 - an organic farmer's open market place in Athens and a farmer's social network for direct delivering of vegetables, belong to the «Face-to-face» initiative.

1- The Viologiki Laiki of Kifissia, is an open air organic farmer's market organised every Monday once a week at the municipality of Kifissia. This open air organic market is located at the northern suburbs around 15 kilometres far from the capital city of Athens and was intended to provide local consumers with healthy and safe agricultural products. The majority of producers-sellers come from the local territory (up to $20 \mathrm{~km}$ ), but there are cases where producers-sellers come from more distant places approximately from up to $200 \mathrm{~km}$. There are about 23 producers and 20 associated farms that take part to the organic farmer's market while there is no estimate of the number of consumers. The "Viologiki Laiki of Kifissia» developed at the local level with the help of the Kifissia municipality. The type of produce is directed according to the needs of a specific group of local consumers in the aforementioned municipality, that of local and organic origin by contributing to and satisfying their quest for healthy and safe products.

The food products range from vegetables, fruits, eggs, honey, bread, pasta, legumes, wine. In terms of the type of farmers involved the majority of them are from the semi-urban area of greater Athens, and range from small to medium farmers. In this open market one can find inhabitants from places nearby Athens who sell overproduction from their household plots or picked wild natural products such as berries and wild or forest greens. Consumers are locally based mainly from the municipality of Kifissia, as well as passers-by. The consumer profile can be identified with the high-income residents of the area of all ages, and of both genders. The direct link between producers and consumers on the market days facilitate their social proximity expressed by honesty and trust between the two parties. Consumers get to know producers in order to have access to the best quality organic products and also by the quality of products the producers are attentive by certain quality standards in order to keep their clients.

In terms of health this particular open market improves access to organic, local, fresh and mainly seasonal products which have at least fewer pesticide residues. The environmental dimension of this initiative may rely on the fact that some small local producers avoid searching for more distant outlets but one cannot exclude the fact that some are coming from far distance regions. In addition the cultivation by some producers of local varieties and not hybrids enhances environmental sustainability (i.e. biodiversity) and innovativeness.

A concluding theme emerging from the above case is that it:

Demonstrates a collective, bottom-up, endogenous process of initiating and implementing change in food systems (e.g. conventional vs organic food system).

2- Horis Messazontes (literally meaning without intermediaries) - www.Agroname.com is a short supply chain and refers to innovative channels of distribution such as direct internet sales of agricultural products to consumers.It is the first online social network for farmers in Greece. The produce comes from farms based in central and northern Greece. It consists of 572 members-staff while 250 different farms are involved. Generally it delivers vegetables, legumes, wine, olive oil and other products and it was founded in Spring of 2012. Apart from consumers and farmers the only other actors involved are the delivery/postal companies/services. Involvement to the network is confirmed through registration to the www.agroname.com site. The website mostly uses the term 'social networking' rather than 'short'. The physical distance is not necessarily shorter than conventional markets or supermarkets. In terms of health and wellbeing the products are seasonal and the customers have benefits from the 'freshness' respect. Environmentally speaking the produce is local-regional and comes mainly from organic farms. The dispatch of small quantities of produce to individual customers is unlikely, however, to be more environmentally friendly than the bulk of sales to supermarket buyers.

Finally, due to the dire Greek economic situation the livelihood of many small to medium scale farmers is at stake, hence the reason for participating in this social initiative possibly enhances their social and economic sustainability. Since this initiative is relatively new, it remains to be seen whether it continues seeing growth in the supply chain mainly due to distribution costs. 
Food Systems at Times of Crisis?

Table 1. Face to Face cases of SFSC

\begin{tabular}{|c|c|c|}
\hline & Viologiki LaikiKifissias, Athens & Social Network HorisMesazontes - «Agroname.com» \\
\hline Type & Organic farmers' market & Farmer initiative for direct delivering of vegetables \\
\hline Activities & $\begin{array}{l}\text { Direct selling of organic food products to consumers by } \\
\text { farmers or wholesalers }\end{array}$ & $\begin{array}{l}\text { On line selling of food products to consumers by post or pick } \\
\text { up procedures }\end{array}$ \\
\hline Funding year & 2005 & Spring 2012 \\
\hline No. of actors & $\begin{array}{c}\text { Involvement of } 23 \text { farmers (selling between } 50-90 \% \text { of their } \\
\text { products) } \\
\text { consumers/customers } \\
\text { Additional } 20 \text { associated farms } \\
\end{array}$ & 572 member-staff, 250 farmers \\
\hline Type of products & Vegetables, fruits, eggs, honey, bread, pasta, legumes, wine & $\begin{array}{l}\text { Vegetables, legumes, wine, olive oil, seeds, aromatic plants, } \\
\text { wheat, fodder }\end{array}$ \\
\hline Area and territory & $\begin{array}{l}\text { From different areas of Greece (from ca. } 15 \mathrm{~km}-\text { ca. } 200 \mathrm{~km} \text { ) } \\
\text { Specific farmers' market based on the northern suburbs of } \\
\text { Athens }\end{array}$ & Central Greece and Northern Greece \\
\hline $\begin{array}{l}\text { What is meant by } \\
\text { short? }\end{array}$ & $\begin{array}{c}\text { Direct from farmer to consumer (usually one farmer present } \\
\text { behind the market bench) }\end{array}$ & $\begin{array}{l}\text { Social networking: reducing social distance through internet } \\
\text { (main information for farmers and consumers) }\end{array}$ \\
\hline $\begin{array}{c}\text { Health \& food } \\
\text { quality }\end{array}$ & $\begin{array}{l}\text { Broad variety of organic fruits and vegetables, local, seasonal } \\
\text { and good quality of products }\end{array}$ & Seasonal agricultural products \\
\hline $\begin{array}{l}\text { Sustainability } \\
\text { issues }\end{array}$ & Certified organic farms $(80 \%)$ & Local, majority of farms organic \\
\hline $\begin{array}{c}\text { Growth \& } \\
\text { development }\end{array}$ & Further growth might be possible & Remain uncertain (distribution costs etc.) \\
\hline $\begin{array}{c}\text { Innovative } \\
\text { elements }\end{array}$ & $\begin{array}{l}\text { Use of local varieties and not hybrids, consumers come to } \\
\text { know the identity of producer and establish relations of trust }\end{array}$ & $\begin{array}{c}\text { Central collection from specific buying points, } 1^{\text {st }} \text { social } \\
\text { engine platform }\end{array}$ \\
\hline
\end{tabular}

\subsection{Proximate Extended SFSC}

The second category of SFSCs is that of Proximate extended initiative. Table 2 describes one proximate extended SFSCs initiative in Greece:Yni-Pirouni is an SME movement that distributes certified organic products produced from local farmers in Chania, Crete since 2012. Although it shares strong characteristics with the spatially extended initiative, geographically it is restricted to the region of Chania-Crete. The disposition of agricultural products is made directly from local producers or through farmers' market points at fixed by producer's price. It also specialises in the delivery of agricultural products mainly organic olive oil to different types of stores all over the country, e.g. Get Bio store in Athens, the urban co-operative 'Sporos' in Athens, the grocery Lancadona in Athens, the 'without intermediaries' co-operative in Thessaloniki, the bio-store Gaea in Chania etc. Adult producers/organic farmers can join the organisation only and if they accept the organisation's rules and regulations. The «YniPirouni» is a key link (intermediary) between producers and consumers with quite distinct goals: a- to sell authentically produced products such as olive oil from the region of Chania, b- to promote fair and environmentally safe concepts through the whole chain, c- to act as a bridge between the producer and consumer (no middleman). The "YniPirouni» is a SME movement with 6 full-time employees and works together with 26 organic farmers from Chania and delivers mainly olive oil to 50 different areas of Greece. «YniPirouni» offers a broad range of organic products mainly vegetables, fruits and legumes produced at the department of Chania. Healthwise: one of its major aims apart from promoting freshness and seasonality of agricultural produce is to distribute high quality and safety products with no pesticide residues safeguarding thus, farmers and consumers health. Environment: «YniPirouni» values high environmental sustainability since farms and processors distribute only organically certified products to different destinations. «YniPirouni's» innovativeness relies on an overall sustainability assessment the so-called Global Standard Food BR, the Quality Assurance ISO 9001: 2000 the Environmental Assurance 14001:2004 and the ISO Guidelines ISO 22000: 2005 (HACCP ). «YniPirouni» is interested to communicate the added value of its products to consumers and retailers promoting in this way a tool that enhances sustainability and health of their products.

Some concluding themes emerging from this case:

In the last few years, there have been some positive signs of continuous development.

Social solidarity is crucial and stimulating.

Future challenge is to respond always to specific quality needs. 
Table 2. Proximate extended SFSC

\begin{tabular}{|c|c|}
\hline & «YniPirouni», Chania, Crete \\
\hline Type & Organic producers initiative/movement \\
\hline Activities & Direct selling of organic products to consumers from farmer's farms to locally based market points, and to social \\
solidarity stores elsewhere in Greece
\end{tabular}

Table 3. Spatially extended SFSC

\begin{tabular}{|c|c|}
\hline & Gaea, Chania Crete \\
\hline Type & Farmer co-operative -firm (limited liability) direct sales to bio-stores \\
\hline Activities & Collection of products directly from regional farms \\
\hline Funding year & 1996 \\
\hline Number of actors & Fruit, vegetables, legumes, eggs, pasta \\
\hline Type of products & Chania, bio-stores product distribution all over the country, mainly big cities \\
\hline Area and territory & Not necessarily local but regional \\
\hline What is meant by short? & Organically certified products, good quality, healthy products \\
\hline Health (food quality) & Organic products, fair price for producers and consumers \\
\hline Sustainability issues & Further services and slow growth (e.g. registration of new members), fair prices vs 'middle man' \\
\hline Growth and development & Members of Gaea cooperative are legible to reduced price of agricultural products, bio-degradable bags. \\
\hline Innovative issues & \\
\hline
\end{tabular}

\subsection{Spatially Extended SFSC}

The last but not least category of SFSCs is the so-called Spatially extended initiative, where the value and meaning laden information about the place of production and producers is transferred to consumers who are outside the region of production itself and who may have no personal experience of that region[2]. In Table 3 a spatially extended SFSC is presented: the organic farmer cooperative-firm of Gaea in Chania, Crete.

Based in Chania (GAEA) is constituted by producers and consumers that aim to spread out the variety of organic products they sell. Price reduction is obtained for members only. Participation to the co-operative-firm is made through a market share process, the price of which is determined by the co-operative's-firm's general assembly and is adjusted every year according to the co-operative's-firm's earnings. It provides fresh produce to bio-stores that are its main customers and consists of 250 members, 28 staff and collaborates with 125 organic farmers from the whole country. The firm came into existence in 1996, but only the last 8 years has witnessed exponential growth. The meaning of shortness in this initiative finds different expressions. The first aim is to establish a direct relationship with local farming in different locales in order to have access to fresh and environmentally sustainable food. Thus, geographical proximity is not important and it is not translated into rigid criteria, but the value and cultural dimension of the produce is strongly linked to the quality and extended location of its production origin which consequently is translated into a fair price. This process along with the yearly adjusted price mechanisms of the firm benefit both producers and consumers enhancing in this way economic sustainability. In terms of sustainability and health aspects the products are fresh and organically certified. The methods of production are organic while the packaging is mainly from reusable materials therefore environmental sustainability is well established. Social sustainability is also crucial and is exemplified by the certified information that accompanies the product. Lack of co-ordination among small organic producers who are spread around the country might have a negative effect on product price hampering the growth of the 
firm. Finally, the question to be asked here is how could this type of organisation be improved?

\section{Discussion}

On the basis of the four Greek SFSCs, this section attempts to provide an initial assessment of the impacts of SFSCs in Greece by utilising four different dimensions of sustainability (social, economic, environmental, health and well being).

When discussing the social impacts of the Greek SFSCs, there is evidence that SFSCs favour the interaction and connection between farmers and consumers, thus promoting the development of trust. Similarly in the UK Ilbery and Maye [27], found that for the producers interviewed, the establishment of good personal relationships with customers was critically important [27]. Furthermore, this particular interaction and connection as exemplified by the Greek schemes relate to social values, principally ensuring quality products to consumers (seasonality: fresh and tasty). Karner [28 p.7] noted that in southern European countries quality is strongly shaped by the context of production including culture, tradition, terrain, climate and local knowledge systems. Whilst all of the Greek case studies generally identify the importance of trusting social relationships associated with SFSCs, the Face-to-Face case of «ViologikiLaiki of Kifissia» and the «Gaea» initiative highlight the potential for the specific food chains to implicitly reinforce social exclusion by targeting urban well educated residents with high incomes.

For example, studies from the USA have identified such a dimension to SFSCs, whereby such initiatives are mainly to preserve middle class and affluent consumers [29]. Also Eaton [30] argues that the adoption of neoliberal policies in urban centres has pushed local food producers towards more elitist, market-led forms of local food projects, undermining earlier neo-communitarian ambitions.

Despite the above 'barriers' to build communities and relationships around the growing and eating of food, the «YniPirouni» initiative promotes the relationship between producers and consumers by organising farm events, revitalising in this way local farming communities in an attempt to develop a sense of community or trusting social relationships between farmers and consumers.

Finally, social networking with the use of internet technology as viewed in the «Agroname.com» case can reduce social distance between farmers and consumers.

Environmental values along with health and well being come second in the promotion messages of Greek SFSCs schemes.

Regarding consumer interest in SFSCs, there is strong evidence that certain consumers are keen to support them. The reasons for such support vary in different countries. There is evidence that consumers associate local produce with higher quality standards, an argument dominant in Mediterranean countries, and want to support - local production - for environmental and ethical (fair trade or support to local economy) reasons [30].

Edwards-Jones[31] suggest that the best option for consumers who have concerns for the health of their environment would be to purchase local products, in season, from producers who use ecologically sound production methods or are certified organic producers.

More important, the methods of production and of processing are crucial for ensuring less environmental impact along with the importance of ethical values in the EU context of SFSCs. The «Viologiki Laiki», the «YniPirouni» and «Gaea» initiatives demonstrate that ethical, social and environmental concerns are in addition to quality aspects the key drivers of consumer interest in this sector.

There is some evidence in the literature that this interest derives from well-educated and wealthy consumers giving thus birth to a certain extent a willingness to pay higher prices, with significant price premium (20\%) [32].

All of the Greek SFSCs have increased knowledge and concern about food amongst consumers with regard to better access to a variety of fruit and vegetables and focus on the promotion of tasty fresh and seasonal food. The «Viologiki Laiki of Kifissia» scheme promotes the use of old non-hybrid varieties (e.g. tomatoes) which are of immense benefit to the local biodiversity and associated with the lack of agrochemicals in the production system [33].

This could also enhance the factor of health and well-being of local and regional consumers.

All four cases of SFSCs have tried to minimized the use of resources as fossil fuel or adopt less polluting methods of production (e.g. practicing organic farming, recycling bags, reduction of 'food miles')[cf. 34]. This of course may vary significantly between different SFSCs. For example, the «Agroname.com» initiative reduces 'food miles' by delivering directly to consumers. But there are no data available on energy efficient for this type of distribution.

Economic sustainability in terms of value added to farmers and support to the local economy is the final crucial element in the sustainability axis. Although clear cut benefits are not easily found in the Greek cases, it can be assumed that some SCFSCs can increase and circulate community income and help preserve small to medium farms in times of crisis as exemplified by the «Agroname.com» and «Yni-Pirouni» case-studies. Synergies with the tourism sector are acknowledged by the «Yni-Pirouni» initiative (e.g. on farm events etc.)

At producer and farm level, the «Agroname.com» «Yni-Pirouni» and «Viologiki Laiki of Kifissia» initiatives seem to allow a higher share of value added to be retained locally, although quantitative evidence of such impacts is poorly documented [cf. 35].

Economic benefits associated with the aforementioned Greek SFSCs, is that of increased income for the producer although empirical research is lacking. It has been suggested by Kneafsey [11 p. 38] that producers are able to add a price premium when selling through SFSCs [11 p. 38], that the 
elimination of the 'middleman' enables farmers to receive a greater share of the profits [11 p. 38] and that SFSCs provide growers with an opportunity to diversify and add value to their produce that would not usually be marketed [11 p. 38].

Overall, when farm-based in rural areas, SFSCs might play an important role in the vitality and quality of life of rural areas promoting implicitly social change through education on sustainability and ethical issues [2].

\section{Conclusions}

On the basis of our analysis we can conclude that there is a variation among different types of SFSCs in Greece and a variation in the degree of sustainability among different types of SFSCs, their products, locations etc. One of the crucial aspects of the debate on SFSCs concerns the possibilities for such schemes to enable producers to survive and to empower them [4], i.e. to prevail in the face of change such as the current economic crisis in Greece and thus build on food resilience schemes and initiatives. But can SFSCs be considered as a «bouncing forward» from the crises subject? [3], or can they be perceived as «a subject protected by the state»? [36].

According to Lekakis and Kousis [37] under austerity policies major concerns centre on legislative changes, e.g. budget reductions on implementing the sustainability framework. This implicitly assumes that Greece cannot use the crisis as an opportunity to increase public spending on alternative forms of SFSCs. But it can carefully delineate the trade - offs inherent in the country's new model of growth, namely agriculture and tourism. Within this framemork, solidarity becomes a far reaching notion than just direct and trustful relations between farmers and consumers: it includes de-commoditised relations to the environment and, to rural and urban territories. It means supporting alternative food supply schemes that demand local democracy and defending the local territory against big infrastructures or privatization of rural public goods. In support to this argument, various participants in SFSCs believe that SFSCs can act as a driver of change and a method to increase sustainability, trust, equality and growth in agriculture, food, business, social, health and rural policy areas.

\section{Acknowledgements}

Results presented in this paper/article have been obtained within the project "Living with Hard Times: How Citizens React to Economic Crises and Their Social and Political Consequences" (LIVEWHAT). This project is/was funded by the European Commission under the $7^{\text {th }}$ Framework Programme (grant agreement no. 613237). Dr. Eugenia Petropoulou is a research member of the Greek team.

\section{REFERENCES}

[1] R. Sonnino, T. Marsden. Beyond the divide: rethinking relationships between alternative and conventional food networks in Europe. Journal of Economic Geography, Vol. 6, No. 2, 181-199, 2006.

[2] H. Renting, M. Shermer, A. Rossi. Civic Food Networks, special issue of International Journal of Sociology of Agriculture and Food, Vol. 19, No. 3, 289-307, 2012.

[3] A. Howell. Resilience as Enhancement: Governmentality and Political Economy beyond 'Responsibilisation', POLITICS, Vol.35, No. 1, 67-71, 2015.

[4] G. Brunori, G., A. Rossi, F. Guidi. (2012). On the new Social Relations around and beyond food. Analysing consumers' role and action in Gruppi di Acquisto Solidale (Solidarity Purchasing Groups, Sociologia Ruralis, Vol. 52, No.1, 1-30, 2012.

[5] T. K. Marsden, J. Banks, G. Bristow. Food supply chain approaches: exploring their role in rural development. SociologiaRuralis, Vol. 40, 424-438, 2000.

[6] G. Brunori, A. Rossi, V. Malandrin. Co-producing transition: Innovation process in farms adhering to solidarity-based purchase groups (GAS) in Tuscany, Italy. International Journal of Sociology of Agriculture and Food, 18, 1, 2011.

[7] H. Renting, T.K. Marsden J. Banks. Understanding alternative food networks: exploring the role of short food supply chains in rural development. Environment and Planning A, Vol. 35, 393-411, 2003.

[8] D. Aubry, L. Kebir. Shortening food supply chains: A means for maintaining agriculture close to urban areas? The case of the French metropolitan area of Paris, Food Policy Vol. 41, 85-93, 2013.

[9] C. Aysoy, H. K. Duygu, T. Semih Tumen. How does a shorter supply chain affect pricing of fresh food? Evidence from a natural experiment, Food Policy 57, 104-113, 2015.

[10] L. Venn, M. Kneafsey, L. Holloway, R. Cox, E. Dowler, and H. Tuomainen. Researching European 'alternative' food networks: some methodological considerations, Area, Vol. 38, No. 3, 248-258, 2006

[11] M. Kneafsey, L. Venn, U. Schmutz, B. Balázs, L. Trenchard, T. Eyden-Wood, E. Bos, G. Sutton, M. Blackett, M. Foodlinks Short food supply chains and local food systems in the EU. A state of play of their socio-economic characteristics, F. Galli, G. Brunori, European Commission Joint Research Centre, Institute for Prospective Technological Studies, Sevilla, Spain, 2013.

[12] O. Canavan, M. Henchion, S. O'Reilly. The use of the Internet as a Marketing Channel for Irish Speciality Food, International Journal of Retail and Distribution Management, Vol. 35, No.2, 178-195, 2007.

[13] P. Mount. Growing local food, scale and local food systems governance. Agriculture and Human Values, Vol. 29, No. 1, 107-121, 2012.

[14] I. Vermeir I. W. Verbeke. Sustainable food consumption: exploring the consumer "attitude - behavioural intention" gap, Journal of Agricultural and Environmental Ethics, Vol. 19, 169-194, 2006. 
[15] F. Randelli. The Role of Consumers in the Transition towards a Sustainable Food Supply. The Case of Gruppi di Acquisto Solidale (Solidarity Purchasing Groups) in Italy, International Journal of Food and Agricultural Economics, Vol. 3 No. 4, 15-26, 2015.

[16] M. Fonte. Food consumption as social practice: Solidarity Purchasing Groups in Rome, Italy. Journal of Rural Studies, Vol. 32, 230-239, 2013.

[17] P. R. Graziano, F. Forno. Political Consumerism and New Forms of Political Participation: The Gruppi di Acquisto Solidale in Italy. The Annals of the American Academy of Political and Social Sciences, Vol. 644, No.1, 121-133, 2012.

[18] F. Forno. P. R Graziano (eds.). Consumerist Culture and Social Movements. Special Issue: Journal of Consumer Culture, Vol.14, No.2, 139-157, 2014.

[19] F. Moulaert, D. MacCallum, A. Mehmood, A. Hamdouch, eds. The International Handbook on Social Innovation: Collective Action, Social Learning and Transdisciplinary Research (Google eBook), Edward Elgar Publishing, 2013.

[20] A. Nicholls, A. Murdock. Social Innovation: Blurring Boundaries to Reconfigure Markets. New York: Palgrave Macmillan, 2012.

[21] H. Renting, M. Schermer, A. Rossi. Building Food Democracy: Exploring Civic Food Networks and Newly Emerging Forms of Food Citizenship, International Journal of Sociology of Agriculture, Vol.19, No.3, 289-307, 2012.

[22] BEPA. Social Innovation. A Decade of Changes. A BEPA report. Bureau of European Policy Advisors. March, 2014, Available at: http://espas.eu/orbis/sites/default/files/generate d/document/en/social_innovation_decade_of_changes.pdf

[23] W. L. Bennet, A. Segerberg (2014). The Logic of Connective Action: Digital Media and the Personalization of Contentious Politics. Cambridge: Cambridge University Press, 2014.

[24] J. Earl, K. Kimport. Digitally Enabled Social Change: Activism in the Internet Age. Cambridge, MA: MIT Press, 2013.

[25] C. Tilly. Remapping Memory: The Politics of Time and Space, Jonathan Boyarin editor, University of Minnesota Press, 1994.

[26] M. Kousis, M. Giugni. Alternative Forms of Resilience Confronting Crisis in Southern Europe: A Social Movements Perspective, in Southern European Society and Politics (forthcoming).
[27] B. Ilbery, D. Maye. Alternative (shorter) food supply chains and specialist livestock products in the Scottish and English border. Environment and Planning A, Vol. 37, No. 5, 823-844, 2005.

[28] S. Karner. Local Food Systems in Europe. Case studies from five countries and what they imply for policy and practice [online]. IFZ. FAAN report Online available from http://www.faanweb.eu/sites/faanweb.eu/files/FAAN_Bookl et_PRINT.pdf, 2010

[29] C. C. Hinrichs, P. Allen. Selective Patronage and Social Justice: Local Food Consumer Campaigns in Historical Context. Journal of Agricultural and Environmental Ethics,Vol. 21, 329-352, 2008.

[30] E. Eaton. From feeding the locals to selling the locale: Adapting local sustainable food projects in Niagara to neocommunitarianism and neoliberalism. Geoforum, Vol. 39, 994-1006, 2008.

[31] G. Edwards-Jones. Does Eating Local Food Reduce the Environmental Impact of Food Production and Enhance Consumer Health? Proceedings of the Nutrition Society, Vol. 69, 582-591, 2010.

[32] C.E. Carpio, C. E. O. Isengildina-Massa, O. Consumer Willingness to Pay for Locally Grown Products: The Case of South Carolina. Selected paper prepared for presentation at the Southern Agricultural Economics Association Annual Meeting, Dallas, TX, February 2-6, 2008, on line available: http://ageconsearch.umn.edu/bitstream/6815/2/sp08ca06.pdf

[33] M. Altieri. The ecological role of biodiversity in agroecosystems, Agriculture, Ecosystems and Environment, Vol. 74, 19-31, 1999.

[34] G. Seyfang. Avoiding Asda? Exploring Consumer Motivations in Local Organic Food Networks. Local Environment, Vol. 13, No. 3, 187-201, 2008.

[35] M. DuPuis, D. Goodman. Should we go 'home' to eat?: Toward a Reflective Politics of Localism. Journal of Rural Studies, Vol. 21, 359-371, 2005.

[36] B. Anderson. What kind of thing is resilience? Politics, Vol. 35 , No. 1, 60-66, 2015.

[37] J. Lekakis, M. Kousis. South European Society and Politics, Online available from http://dx.doi.org/10.1080/13608746.2013.799731, 2013. 